\title{
Findings from a mixed methods study of an interprofessional faculty development program
}

\author{
Erin Abu-Rish Blakeney, Andrea Pfeifle, Mandy Jones, Leslie Walter Hall\& Brenda K. Zierler
}

\begin{abstract}
Forty faculty members from eight schools participated in a year-long National Faculty Development Program (NFDP), conducted in 2012-2013, aimed at developing faculty knowledge and skills for interprofessional education (IPE). The NFDP included two live conferences. Between conferences, faculty teams implemented self-selected IPE projects at their home institutions and participated in coaching and peer-support conference calls. This paper describes program outcomes. A mixed methods approach was adopted. Data were gathered through online surveys and semi-structured interviews. The study explored whether faculty were satisfied with the program, believed the program was effective in developing knowledge and skills in designing, implementing and evaluating IPE, and planned to continue newlyimplemented IPE and faculty development. Peer support and networking were two of the greatest perceived benefits. Further, this multi-institutional program appears to have facilitated early organizational change by bringing greater contextual understanding to assumptions made at the local level that in turn could influence hidden curricula and networking. These findings may guide program planning for future faculty development to support IPE.
\end{abstract}

Keywords: Faculty Development, Interprofessional, Team-Based Care, Evaluation, Qualitative, Mixed Methods, Interviews

This is the author's manuscript of the article published in final edited form as:

Blakeney, E. A.-R., Pfeifle, A., Jones, M., Hall, L. W., \& Zierler, B. K. (2016). Findings from a mixed-methods study of an interprofessional faculty development program. Journal of Interprofessional Care, 30(1), 83-89. http://doi.org/10.3109/13561820.2015.1051615 


\section{Introduction}

Interprofessional team-based care continues to grow, with increasing recognition that health outcomes improve when different professions work together (Grumbach \& Bodenheimer, 2004; Interprofessional Education Collaborative Expert Panel, 2011; Leape, et al., 2009; Reeves, Perrier, Goldman, Freeth, \& Zwarenstein, 2013; Wagner, 2000; Bodenheimer, Wagner, \& Grumbach, 2002). Requirements for interprofessional education (IPE) have thus been integrated into accreditation standards in many disciplines (Zorek \& Raehl, 2013), and health professions schools are seeking ways to develop faculty to teach and evaluate IPE outcomes. For the purpose of this paper, “faculty” includes academic educators, clinician educators, and preceptors.

Faculty preparation has been identified as a key factor supporting IPE success (Ho et al., 2008); however faculty development (FD) has historically included instructional design, teaching effectiveness, and evaluation strategies for uniprofessional education (Steinert, 2005). Most faculty members have not been trained to teach and facilitate interprofessional learning groups (Sargeant, Hill \& Breau, 2010) and may possess diverse attitudes and values that act as barriers to IPE success (Steinert, 2005). Additional preparation is needed for faculty to effectively model and facilitate IP learning (IPEC, 2011).

While most FD literature focuses on interventions directed toward single professions, emerging conceptual frameworks for IPE suggest these programs be aimed at individual and organizational levels, involve diverse stakeholders, and align the context for learners and learning with administrative, accreditation and institutional structures (Leslie, Baker, Egan-Lee, Esdaile \& Reeves, 2013; Ruiz, Exer \& Purden, 2013; Shrader, Mauldin, Hammad, Mitcham \& Blue, 2015; Silver \& Leslie, 2009). Similarly, evidence for best practices in FD for IPE is expanding (Buring et al., 2009; Steinert, et al., 2010; Engbers, de Caluwe, Stuyt, Fluit, Bolhuis, 
2013; Hall \& Zierler, 2015). Successful FD for IPE should utilize diverse educational methods grounded in adult learning theories (Shrader et al., 2015), and include experiential and peer learning, reflection, and feedback (Steinert, Naismith, \& Mann, 2012). Hence, faculty learners should be educated in interprofessional teams that model interprofessional collaboration (Steinert, 2005).

Emerging research describing outcomes for purposeful FD in IPE primarily describes programs implemented at one institution or at several institutions but within the same profession (Christofilos, DeMatteo \& Penciner, 2014; Shrader, et al., 2015; Buring, et al., 2009; Hall \& Zierler, 2015). Hence, there is limited generalizable knowledge available describing effective pedagogical approaches, learning outcomes, or program impact. Responding to this lack of evidence, a year-long multi-institutional National Faculty Development Program (NFDP) was piloted in 2012-2013. The NFDP was designed to develop faculty knowledge and skills and provide experience in IPE planning, implementation and facilitation, thereby enhancing participants’ abilities to replicate or enhance IPE at their institutions.

The NFDP was grounded in experiential and social learning theories. Experiential learning theory (ELT) draws on the work of several well-known $20^{\text {th }}$ century scholars and others who made experience central to their theories of human development and learning (Kolb, 1984). ELT defines learning as "the process whereby knowledge is created through the transformation of experience. Knowledge results from the combination of grasping and transforming experience” (Kolb, 1984, p. 41).

Social learning theory (SLT) posits that learning is a cognitive process that takes place in a social context (Bandura, 1963). Ball State University incorporated SLT into ELT and systematically extended their application to interdisciplinary teams participating in "immersive 
learning” projects (Sanyal, 2012; Gora, 2007a; Gora, 2007b). Building upon this work, the NFDP included immersive and project-based learning, peer support, and just-in-time training.

Study objectives were to describe NFDP outcomes and to summarize participants' feedback on program usefulness and desirability of program expansion and/or continuation. Drawing from Freeth, Hammick, Koppel, Reeves, and Barr’s (2002) expansion of Kirkpatrick’s Model for Learning Outcomes (1994), we hypothesized that participants would report satisfaction, learning, transfer, and impact outcomes for themselves and their organizations and would recommend program expansion and/or continuation.

\section{Background}

The NFDP was a grant-supported pilot project to train faculty to deploy interprofessional training in team-based care. The program was co-led by the University of Washington (UW) and University of Missouri (MU), partnering with six additional universities: Columbia University (New York), Medical University of South Carolina (MUSC), University of Kentucky (UK), University of North Dakota (UND), University of Virginia (UVA), and Indiana University (IU). Program objectives were to:

1) Successfully implement elements of a one year curriculum in IP team-based care at academic health centers (AHCs).

2) Pilot a FD program in team-based care with eight committed AHCs, learning with and from each other, thus preparing faculty as institutional leaders and innovators in IPE.

3) Draw upon the knowledge/experiences of participants to consolidate new learning regarding effective IP faculty development.

4) Use outcomes to produce a roadmap for possible future interprofessional FD.

A small group of experienced IPE leaders worked with grant co-PI's to plan two live conferences and assist with evaluation. The NFDP started with a 3.5 day training conference in Seattle, WA in March, 2012 and ended with a 1.5 day training/reporting conference in Columbia, 
MO in February, 2013. Described previously, ELT (Kolb, 1984; Sargeant, 2009) and SLT (Bandura, 1963) guided core instructional activities. Theoretical approaches to teaching and evaluating IPE were shared in short didactic bursts, followed by participation in interactive exercises, and immersion in preplanned IPE activities with health professions’ students. Faculty participants debriefed after each learning activity to consolidate lessons learned (Sargent, 2009).

Prior to each conference, participants completed assigned readings. Between conferences, teams implemented new IPE at their home institutions. A secure website allowed NFDP participants to share resources (curriculum, faculty guides, and evaluation tools) and contributed to a cross-institutional learning community. Conference calls occurred every six weeks throughout the program. These calls were designed to enable: coaching and social learning, sharing lessons learned, discussing evaluation strategies, addressing barriers encountered while implementing IPE, and sharing information about upcoming IPE opportunities.

\section{Methods}

This convergent mixed methods study (Creswell \& Plano Clark, 2011) built upon data collected from an online survey (Web Appendix A) ${ }^{1}$ and information obtained during semistructured telephone interviews with participants.

\section{Study participants}

Faculty participants from one private and seven public institutions were intentionally drawn from different regions of the United States. Three to four individuals from each 
institution entered the NFDP as an interprofessional team for a total of eight teams and forty participants.

\section{Data collection}

Part 1 (Online Survey): All NFDP participants (N=40) were invited in February 2013 to complete a web-based online survey that was developed based on topics identified by participants during discussions about program relevance, outcomes and evaluation strategies. The survey consisted of 33 Likert-style multiple choice and short answer questions. Twenty-six participants completed the survey (response rate $=65 \%$ ), resulting in a convenience sample of nursing, physician assistant, medicine, and pharmacy faculty with varying levels of IPE experience (five with $<1$, nine with $2-4$, six with 5-7 and five with $8+$ years). Respondents indicated the extent to which they believed NFDP objectives were met and described perceived benefit of select components.

Part 2 (Semi-structured Phone Interview): At least one NFPD participant from each institution was invited to participate in a semi-structured phone interview, creating a purposive sample ( $\mathrm{n}=15)$ that reflected diversity in disciplines and IPE experience levels (Given, 2008a). Eleven of the 15 individuals participated in a 30-60 minute interview focusing on the experience and perceived impact of the NFDP, specifically describing whether their ability to lead and deliver IPE had changed. The length and flow of interviews followed an iterative process; questions were ordered and topics were further probed based upon interviewees' responses (Given, 2008b) (Web Appendix A).

\section{Data Analysis}


Descriptive statistics were used to summarize survey results. The research team identified themes and subthemes from text responses to short answer questions.

Interviews were audio-recorded, transcribed, and reviewed twice to ensure accuracy. These data were analyzed to identify and summarize themes and subthemes using constant comparative analysis and grounded theory (Web Appendix B), as described by Charmaz (2000) and Glasser (1965). Three researchers independently reviewed transcripts to identify emerging themes and subthemes, and consensus was reached through discussion. Preliminary themes and subthemes were member-checked with five NFDP participants from different institutions, finalized, and entered into a tracking document.

Triangulation of data obtained from interview transcripts, survey responses, and member checking was utilized to ensure validity, clarify themes that could be collapsed, and identify subthemes. A codebook with definitions and exemplar quotes was developed (Web Appendix B). Defining themes and subthemes with specific exemplar quotes added context to the analysis; this approach is frequently used to enhance reliability and validity during qualitative analysis (Creswell, 2009).

\section{Ethical considerations}

The convergent mixed methods study (Creswell \& Plano Clark, 2011) received approval from the UW Human Subjects Division and the MU Health Sciences institutional review board.

\section{Results}

Online Surveys 
Overall, $100 \%$ of survey respondents reported that the NFDP: 1) prepared them to more effectively teach interprofessional team-based care, 2) provided support for implementing IPE, and 3) positively impacted themselves, their colleagues, and their institutions (Table 1). The majority of participants (84\%) included explicit FD activities as a complement to new IPE offerings implemented at their sites, including: 1) didactic materials (e.g. faculty guides, n=10); 2) hands-on workshops or simulations ( $n=10)$; and 3) Just-in-Time Trainings in advance of IPE activities ( $\mathrm{n}=10)$. Many of these FD activities were modeled after those used in the NFDP.

All participants implemented IPE activities at their sites—-four implemented IP error disclosure; remaining sites employed unique IP activities, including narrative medicine and team-based clinical problem solving. Approximately one-third (32\%) of participants encountered barriers to meeting program goals, including: competing responsibilities; variable institutional support (especially when changing schedules); and insufficient time to develop facilitation skills during the live conferences (Table 1).

Table 1: Impacts, Supports, and Barriers

\begin{tabular}{|c|c|c|}
\hline & $\begin{array}{l}\text { Yes } \\
{[n,(\%)]}\end{array}$ & $\begin{array}{l}\text { No } \\
{[n,(\%)]}\end{array}$ \\
\hline $\begin{array}{l}\text { I feel better prepared to teach team-based care as a result of my } \\
\text { participation in this program. }\end{array}$ & $\begin{array}{l}26 \\
(100)\end{array}$ & $\begin{array}{l}0 \\
(0)\end{array}$ \\
\hline $\begin{array}{l}\text { Did you encounter supports in achieving your goals for } \\
\text { participation in this faculty development program? }\end{array}$ & $\begin{array}{l}26 \\
(100)\end{array}$ & $\begin{array}{l}0 \\
(0)\end{array}$ \\
\hline $\begin{array}{l}\text { Did you encounter any barriers in achieving your goals for } \\
\text { participation in this faculty development program? }\end{array}$ & $\begin{array}{l}8 \\
(32.00)\end{array}$ & $\begin{array}{l}17 \\
(68.00)\end{array}$ \\
\hline $\begin{array}{l}\text { Do you feel that your participation in the national faculty } \\
\text { development program has had an identifiable impact on your } \\
\text { colleagues at your home institutions? }\end{array}$ & $\begin{array}{l}26 \\
(100)\end{array}$ & $\begin{array}{l}0 \\
(0)\end{array}$ \\
\hline $\begin{array}{l}\text { Did you do any faculty development at your site as part of your } \\
\text { school's project? }\end{array}$ & $\begin{array}{l}21 \\
(84.00)\end{array}$ & $\begin{array}{l}4 \\
(16.00)\end{array}$ \\
\hline $\begin{array}{l}\text { As a result of your participation in the national faculty } \\
\text { development program, do you have future plans for faculty } \\
\text { development at your site? }\end{array}$ & $\begin{array}{l}24 \\
(96.00)\end{array}$ & $\begin{array}{l}1 \\
(4.00)\end{array}$ \\
\hline
\end{tabular}


Respondents were satisfied with the pedagogical approaches and were universally positive about the prospect of participating in similar future programs and recommending the program to others. All participants reported that the NFDP provided important opportunities to network and receive feedback from others (Table 2).

Table 2: Program Structure and Networking

\begin{tabular}{|c|c|c|c|c|}
\hline & \begin{tabular}{|l|} 
Strongly \\
Disagree \\
{$[n,(\%)]$} \\
\end{tabular} & $\begin{array}{l}\text { Disagree } \\
{[\mathrm{n},(\%)]}\end{array}$ & $\begin{array}{l}\text { Agree } \\
{[n,(\%)]}\end{array}$ & $\begin{array}{l}\text { Strongly } \\
\text { Agree } \\
{[\mathbf{n},(\%)]}\end{array}$ \\
\hline $\begin{array}{l}\text { If given the opportunity-based on the effort } \\
\text { required versus the benefit gained-I would } \\
\text { participate in this 11-month national faculty } \\
\text { development program again. }\end{array}$ & $\begin{array}{l}0 \\
(0)\end{array}$ & $\begin{array}{l}0 \\
(0)\end{array}$ & $\begin{array}{l}4 \\
(15.38)\end{array}$ & $\begin{array}{l}22 \\
(84.62)\end{array}$ \\
\hline $\begin{array}{l}\text { I would recommend the experience of } \\
\text { participating in this national faculty } \\
\text { development program to others. }\end{array}$ & $\begin{array}{l}0 \\
(0)\end{array}$ & $\begin{array}{l}0 \\
(0)\end{array}$ & $\begin{array}{l}3 \\
(11.54)\end{array}$ & $\begin{array}{l}23 \\
(88.46)\end{array}$ \\
\hline $\begin{array}{l}\text { The mix of hands on and didactic } \\
\text { teaching/learning in the national faculty } \\
\text { development program was useful. }\end{array}$ & $\begin{array}{l}0 \\
(0)\end{array}$ & $\begin{array}{l}0 \\
(0)\end{array}$ & $\begin{array}{l}6 \\
(23.08)\end{array}$ & $\begin{array}{l}20 \\
(76.92)\end{array}$ \\
\hline $\begin{array}{l}\text { Periodic coaching calls and checking in with the } \\
\text { mentorship team was helpful. }\end{array}$ & $\begin{array}{l}0 \\
(0)\end{array}$ & $\begin{array}{l}0 \\
(0)\end{array}$ & $\begin{array}{l}17 \\
(68.00)\end{array}$ & $\begin{array}{l}8 \\
(32.00)\end{array}$ \\
\hline $\begin{array}{l}\text { My network of IPE contacts expanded at my site } \\
\text { during the course of my participation in the } \\
\text { national faculty development program. }\end{array}$ & $\begin{array}{l}0 \\
(0)\end{array}$ & $\begin{array}{l}1 \\
(3.85)\end{array}$ & $\begin{array}{l}7 \\
(26.92)\end{array}$ & $\begin{array}{l}18 \\
(69.23)\end{array}$ \\
\hline $\begin{array}{l}\text { My network of IPE contacts expanded beyond } \\
\text { my site during the course of my participation in } \\
\text { the national faculty development program. }\end{array}$ & $\begin{array}{l}0 \\
(0)\end{array}$ & $\begin{array}{l}0 \\
(0)\end{array}$ & $\begin{array}{l}3 \\
(11.54)\end{array}$ & $\begin{array}{l}23 \\
(88.46)\end{array}$ \\
\hline $\begin{array}{l}\text { I feel more comfortable reaching out to } \\
\text { participants from other sites for support than } \\
\text { prior to participation in the program. }\end{array}$ & $\begin{array}{l}0 \\
(0)\end{array}$ & $\begin{array}{l}0 \\
(0)\end{array}$ & $\begin{array}{l}2 \\
(7.69)\end{array}$ & $\begin{array}{l}24 \\
(92.31)\end{array}$ \\
\hline
\end{tabular}

\section{Semi-structured interviews}

Respondents described participation in the NFDP as beneficial and valuable. Two themes emerged: 'Results and benefits (of participating)' and 'Lessons learned (effective pedagogical approaches to FD for IPE and for implementing IPE activities)'. Themes and 
component subthemes, are summarized in Figure 1. Exemplar quotes are described in the narrative below and in Web Appendix B.

Figure 1: Themes Organized by Sub-Themes

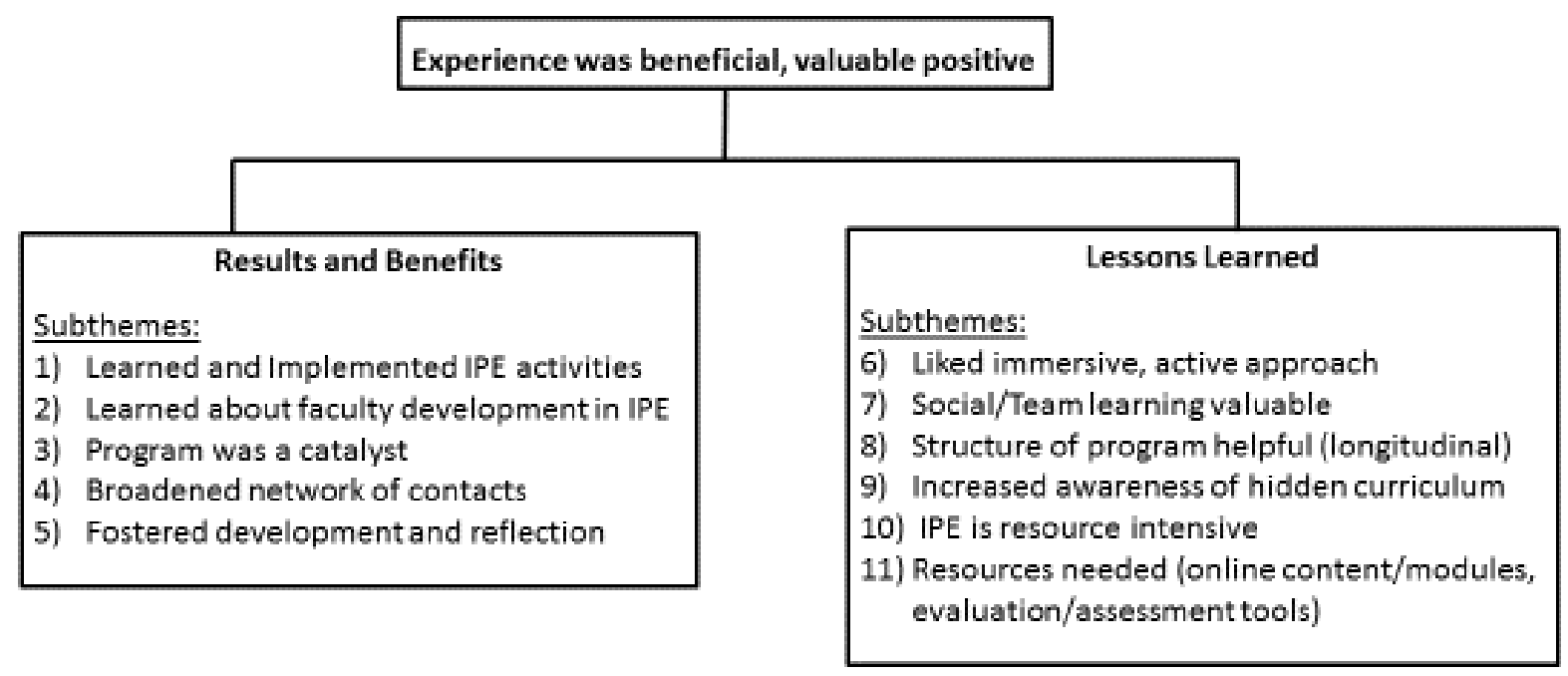

Results and Benefits (Theme 1)

Five major subthemes emerged relating to results and benefits of the NFDP. All participants developed and implemented an IPE project at their home institutions during the program (subtheme 1). Some implemented an error disclosure module modeled during the first conference, while others developed new projects conceived during the NFDP.

“...this really helped us to develop new ideas, network with other institutions on the grant and to actually substantially improve our course and our faculty development."(R7)

Further, participants learned about, planned for, and many subsequently implemented, FD to support IPE at their home institutions (subtheme 2):

"...we created a lot more excitement about it and a lot more interest and it also got us thinking about making our facilitator training a lot simpler.” (R7)

Regardless of the project, participation in the NFDP supported successful implementation of IPE (subtheme 3). In addition to having plans for future FD and IPE activities, participants 
expressed interest in being part of an ongoing national FD collaboration or "train-the-trainer" programs.

“... we have several things directly in our school that are emerging as new activities...” (R4)

“....the group has actually become a functional working group to get a whole body of IPE activities up and running next year in a much more cohesive and coherent way.” (R2)

Participants described positive impacts of broadening their IPE network and developing new relationships and collaborations within and outside of their home institutions (subtheme 4).

"I wouldn't have remotely known where to start a year ago, and now, I feel like, I'm very comfortable reaching out to other faculty members within our own college, outside of our college and even different universities...”(R5)

Participants reported that the NFDP fostered personal development and self-reflection (subtheme 5). They described feeling inspired and that the experience helped them progress from novice to more experienced educators.

“...really enhanced my own personal ability to teach quite a bit..... those kinds of discussions [during the NFDP conferences] really made me step back and look at what I do during all of my teaching to make sure I'm not giving inadvertent messages...” (R2)

"I think that I've probably focused more on team function in my teaching with medical students and residents. I've actually had a huge shift in the last couple of years in the emphasis that I think should be put on communication skills...” (R10)

Lessons Learned/Pedagogical Approaches (Theme 2)

Many participants reported acquiring new knowledge and skills from the NFDP.

Underlying subthemes describe lessons learned about effective pedagogical approaches and FD for IPE. A universal subtheme that emerged was that participants liked the immersive, active learning approach (subtheme 6) used throughout the program.

"There is only so much that you can absorb from sitting in lectures or participating in a workshop... I think having the faculty development program occur over the 
timeframe of when there were actual, real student activities going on was a huge benefit.” (R5)

Participants reported value in social learning and indicated this as an effective strategy

for FD in IPE (subtheme 7).

"I think the opportunity to have in-depth discussions with other people who were also concerned with some of the same issues, some who were a little further along than we are, some who were in a similar position in terms of, you know, by how far we are in the development."(R4)

"Yes. I think it's been positive just to know that there is a real movement here of people interested in IPE...” (R6)

Additionally, participants described the longitudinal structure of the program as being helpful/productive (subtheme 8). Specifically, coaching calls and check-ins with a mentorship team were among the resources most valued:

"What [the conference calls] served to do is keep the issue in my mind and kind of keep us on track.... It helps you with accountability and helps you keep your energy level and your enthusiasm for the projects." (R4)

"I felt like they were very informative and it was good to be involved in those because I felt like it really kept what we were doing throughout the year on the forefront." (R8)

Further, participants would have liked more time together with their own teams while at the live conferences:

“...Some more time to spend just talking within our group..., Just to kind of debrief." (R1)

"the way that we could improve the actual, in-person experience was to allow us more time to work in groups... we did a lot of hypothetical experiences and different games and things like that. I think it would have also been very useful to workshop our own programs with other people...” (R6)

Participants described becoming more aware of the hidden curriculum associated with IPE (subtheme 9), meaning they became aware that: 1) they and other faculty members can send unintended messages about their own or other professions (e.g. through use of biased 
terminology and/or hierarchical communication styles), and 2) students can experientially learn the value of teamwork without that being the explicit focus of learning activities. Participants reported that this increased awareness of hidden curricula resulted in their own behavioral changes.

"Those kinds of discussions really made me step back and look at what I do during all of my teaching to make sure that I'm not giving inadvertent messages and not the message I want to get across." (R2)

"[what] resonates with me is the difference between the implicit and explicit curriculum... I never thought about doing IPE where you're not explicitly telling [students] the things we want them to get out of it." (R5)

Most participants found planning and implementing IPE to be resource-intensive (subtheme 10). Barriers included lack of time and competing responsibilities, difficulty in scheduling, and funding:

"From our own work, it’s just mainly being over-committed. Everything always takes more time than you think. " (R1)

“...The last thing I took away from it was the difficulty involved and the complexity involved in implementing IPE...” (R5)

Participants reported that having on-line access to curricular content, modules, and assessment tools was useful, easy, and user-friendly (subtheme 11):

"I have used the online materials to help reference other people to what we're doing and I also used that same template as a way of thinking of future activities that I'm going to be doing." (R2)

\section{Discussion}

Results indicate that the NFDP was effective in preparing faculty for IPE and to teach teambased care, and positively impacted participants and their institutions. Faculty reported that they became more involved with IPE, improved or developed new IPE activities, received funding to 
explore outcomes from IPE, and/or had been invited into IPE leadership roles at their institutions, including two who became IPE center directors.

This study provides insight into one experiential and social learning theory-based pedagogical approach employed in a successful longitudinal FD program. The team learning environment and combination of didactic training and immersive real-time IPE activities were essential elements of the curricula (Hall \& Zierler, 2015). In particular, this study indicated the utility of live meetings with other faculty learners coupled with periodic check-ins where learners received coaching or engaged in peer discussions about their IPE work. Peer support and networking emerged as one of the most beneficial aspects of the program and has led to subsequent productive collaborations.

As we strive to improve the healthcare experience, the health of populations, and reduce health care costs (Berwick, Nolan \& Whittington, 2008; Institute for Healthcare Improvement, 2014), health professions education programs must keep pace with the rapidly changing health care environment. The National Center for Interprofessional Practice and Education (NCIPE) has been developed to support and accelerate these efforts (http://nexusipe.org/). An explicit goal of the NCIPE Nexus - the integration of IPE within the context of interprofessional practice - is to address FD needs, including gathering and disseminating data to validate improved pedagogical approaches. Results from the NFDP should be considered along with other models for effective FD as we seek coordinated national strategies to equip faculty for IPE and promote team-based care.

NFDP participants reported gains in knowledge and skills and changes in attitudes, teaching behavior, and organizational practice (Steinert, et al., 2006). When considered from the perspective of the expanded Kirkpatrick Model for Learning outcomes (Kirkpatrick, 1994; 
Freeth et al., 2002), these results suggest that the NFDP was effective in attaining learning outcomes at the Reaction, Learning, Behavior, and Results levels. The expanded model includes sublevels for Learning (level 2) and Results (level 4) and defines impacts on results as a change in the system or organizational practice attributable to the educational program. NFDP participants reported Kirkpatrick level 4-type outcomes, including: 1) implementing new IPE activities (training hundreds of students), 2) creating and/or expanding FD programs (thereby training other faculty at their institutions), 3) receiving grant funding to research quality-related outcomes in IPE (including a UK - IU collaboration resulting from the NFDP) and 4) participants moving into new positions of leadership/directorship.

Peer learning and the creation of a learning community have been described as essential elements of successful FD programs (Steinert et al., 2006; O’Sullivan \& Irby, 2011). Experiential and social learning approaches, adherence to adult learning principles, the provision of feedback, and use of diverse instructional methods all likely contributed to NFDP success as they have in other single profession or single institution FD programs (Buring et al., 2009, Christofilos et al., 2014; Shrader et al., 2015). This study is unique compared to the majority of interprofessional FD programs in that it was multi-institutional, and participant experiences were similar across all participating institutions.

Participants also reported an increased awareness of and appreciation for the importance of attending to the "hidden curriculum" when teaching interprofessionally. These observations are important when considered in conjunction with observations reported by Thiedke, Blue, Chessman, Keller and Mallin (2014) wherein students reported clinical faculty behaviors as influencing their own practices, even when those behaviors were only observed during patient care under busy circumstances. 
Most participants found planning and implementing IPE to be resource-intensive (subtheme 10), which is consistent with previous research (Khalili, Hall, \& DeLuca, 2014; Buring et al., 2009; Lawlis, Anson, \& Greenfield, 2014; Hall \& Zierler, 2015). Barriers included lack of time, competing responsibilities, scheduling difficulty, and funding, similar to barriers described by Christophilos et al., 2014. Provision of shared resources to NFDP participants such as a shared network of didactic content, case-banks, assessment tools and regular check-ins were important supports for faculty. Additionally, the extension of the program over one year helped participants to stay accountable to their long-term personal development and IPE outcome goals. Longitudinal programs have been shown to produce outcomes not seen in one-time interventions (e.g., stronger peer networks and collaborative relationships) and are more often associated with Kirkpatrick level 4 outcomes (Steinert et al., 2006). These results support findings in other studies of interprofessional FD programs in that a longitudinal structure combined with a variety of pedagogical approaches grounded in adult learning theory are key elements of successful programs (Christofilos et al., 2014; Shrader et al., 2015). More research is needed to determine the optimal duration of programs to result in long-term changes and durable outcomes.

There are a number of limitations to this study. Researchers were involved in the NFDP as participants and/or facilitators, which could have introduced bias or influenced respondents. However, as participants provided both positive and negative feedback, their responses did not appear to be constrained. Further limitations include the small sample size which limits the validity and generalizability of these findings, the use of volunteers as subjects, and use of selfreported data. For example, in terms of generalizability, NFDP participants were self-selected with demonstrated interest, motivation, and current engagement in IPE. This strong linkage 
between IPE leadership roles and the overwhelmingly positive responses to the program must be considered if seeking to apply these lessons broadly to others.

\section{Concluding comments}

The NFDP met a need in terms of developing faculty for IPE and was successful in meeting its goals. The mixed methods study provided information about similarities and differences in participant experiences. Participant feedback identified which elements of this program were most successful and generated recommendations for ongoing program improvement. As such, this program may serve as a model for broader national FD efforts or for other institutions implementing such programs.

\section{Note}

1. See Web Appendix A and related web appendices at http://collaborate.uw.edu/resources-andpublications/ipe-resources/we-want-more-findings-from-an-interprofessional-faculty-dev ).

Acknowledgements: We would like to acknowledge the support of all participants in the National Faculty Development, including: the NFDP Member Check Team (James Ballard, Amy Blue, Leslie Hall, Eric Johnson, Valentina Brashers, Brenda Zierler). We would also like to acknowledge Barbara Brandt for her insights into broader implications of this work in relation to the National Center for Interprofessional Practice and Education (Nexus).

Declaration of Interest: This work was funded by grants from the Josiah Macy Jr. Foundation (Grant Number B12-04: Interprofessional Faculty Development in Team-based Care) and Hearst Foundations. The authors report no conflicts of interest. The authors alone are responsible for the content and writing of the paper. 


\section{References:}

Bandura, A. (1963). Social learning and personality development. New York, NY: Hold, Rinehart, and Winston.

Berwick, D. M., Nolan, T. W., \& Whittington, J. (2008). The triple aim: Care, health, and cost. Health Affairs (Millwood), 27(3), 759-769. doi: 10.1377/hlthaff.27.3.759

Bodenheimer, T., Wagner, E.H., \& Grumbach, K. (2002). Improving primary care for patients with chronic illness: The chronic care model, part 2. JAMA, 288(15), 1909-1914. http://dx.doi.org/10.1001/jama.288.15.1909

Buring, S. M., Bhushan, A., Brazeau, G., Conway, S., Hansen, L., \& Westberg, S. (2009). Keys to successful implementation of interprofessional education: Learning location, faculty development, and curricular themes. American Journal of Pharmaceutical Education,73(4), article 60. http://dx.doi.org/10.5688/aj730460

Charmaz, K. (2000). Grounded theory: Objectivist and constructivist methods. In N. Denzin \& Y. Lincoln (Eds.), Handbook of qualitative research (pp. 259-380). Thousand Oaks, CA: Sage Publications, Inc.

Christofilos, V., DeMatteo, D., \& Penciner, R. (2014). Outcomes of commitment to change statements after an interprofessional faculty development program. Journal of Interprofessional Care, 1-3. http://doi.org/10.3109/13561820.2014.950725

Creswell, J.W. (2009). Research design: Qualitative, quantitative and mixed methods approaches ( $3^{\text {rd }}$ edition). Thousand Oaks, CA: Sage Publications, Inc.

Creswell, J.W. \& Plano Clark, V.L. (2011). Designing and conducting mixed methods research ( $2^{\text {nd }}$ edition). Thousand Oaks, CA: Sage Publications, Inc. 
Engbers, R., de Caluwé, L. I. A., Stuyt, P. M. J., Fluit, C. R. M. G., \& Bolhuis, S. (2013). Towards organizational development for sustainable high-quality medical teaching. Perspectives on Medical Education, 2(1), 28-40. doi: 10.1007/s40037-013-0043-6

Freeth, D., Hammick, M., Koppel, I., Reeves, S. \& Barr, H. (2002). A critical review of evaluations of interprofessional education: Occasional paper no. 2. Higher Education Academy. Available from http://www.hsaparchive.org.uk/rp/publications/occasionalpaper/occp2.pdf/at_download/fi le.pdf

Given, L. M. (Ed.). (2008a). Purposive sampling. In The SAGE Encyclopedia of Qualitative Research Methods (Vol. 2, pp. 697-698). Thousand Oaks, CA: SAGE Publications.

Given, L. M. (Ed.). (2008b). Semi-structured interview. In The SAGE Encyclopedia of Qualitative Research Methods (Vol. 2, pp. 810-811). Thousand Oaks, CA: SAGE Publications.

Glasser, B. (1965). The constant comparative method of qualitative analysis. Social Problems, 12(4), 436-445. http://dx.doi.org/10.1525/sp.1965.12.4.03a00070

Gora, J.M. (October, 2007a). Ivory towers no more. University Business. Retrieved from: http://www.universitybusiness.com/article/ivory-towers-no-more

Gora, J.M. (February, 2007b). Ball State University’s immersive learning. University Business. Retrieved from: http://www.universitybusiness.com/article/ball-state-universitysimmersive-learning

Grumbach, K., \& Bodenheimer, T. (2004). Can health care teams improve primary care practice? JAMA, 291(10), 1246-1251. http://dx.doi.org/10.1001/jama.291.10.1246 
Hall, L.W., \& Zierler, B. K. (2015). Interprofessional education and practice guide no. 1;

Developing faculty to effectively facilitate interprofessional education. Journal of Interprofessional Care, 29 (1), pp. 3-7doi:10.3109/13561820.2014.937483

Ho, K., Jarvis-Selinger, S., Borduas, F., Frank, B., Hall, P., Handfield-Jones, R., Hardwick, D.F., Lockyer, J., Sinclair, D., Lauscher, H.N., Ferdinands, L., MacLeod, A., Robitalle, M.A., \& Rouleau, M. (2008). Making interprofessional education work: the strategic roles of the academy. Academic Medicine, 83(10), 934-940. doi: 10.1097/ACM.0b013e3181850a75

Institute for Healthcare Improvement. (2014). Improving health and healthcare worldwide. Retrieved from: http://www.ihi.org Interprofessional Education Collaborative Expert Panel (IPEC). (2011). Core competencies for interprofessional collaborative practice: Report of an expert panel. Interprofessional Education Collaborative. Retrieved from: http://www.aacom.org/InfoFor/educators/ipe/Documents/CCrpt11-19-11.pdf

Khalili, H., Hall, J., \& DeLuca, S. (2014). Historical analysis of professionalism in western societies: Implications for interprofessional education and collaborative practice. Journal of Interprofessional Care, 28(2), 92-97. doi: 10.3109/13561820.2013.869197

Kirkpatrick, D. L. (1994). Evaluating training programs: The four levels. San Francisco, CA: Berrett-Koehler.

Kolb, D. A. (1984). Experiential learning: Experience as the source of learning and development. New Jersey: Prentice-Hall 
Lawlis, T. R., Anson, J., \& Greenfield, D. (2014). Barriers and enablers that influence sustainable interprofessional education: a literature review. Journal of Interprofessional Care, 28(4), 305-310. doi: 10.3109/13561820.2014.895977

Leape, L., Berwick, D., Clancy, C., Conway, J., Gluck, P., Guest, J., Lawrence, D., Morath, J., O’Leary, D., O’Neill, P., Pinakiewicz, D., \& Isaac, T. (2009). Transforming healthcare: A safety imperative. Quality and Safety in Health Care, 18(6), 424-428. http://dx.doi.org/10.1136/qshc.2009.036954

Leslie, K., Baker, L., Egan-Lee, E., Esdaile, M., \& Reeves, S. (2013). Advancing faculty development in medical education: a systematic review. Academic Medicine, 88(7), 1038-45. doi: 10.1097/ACM.0b013e318294fd29

O’Sullivan, P. S., \& Irby, D. M. (2011). Reframing research on faculty development. Academic Medicine, 86(4), 421-428. doi: 10.1097/ACM.0b013e31820dc058

Reeves, S., Perrier, L., Goldman, J.H., Freeth, C., \& Zwarenstein, M. (2013). Interprofessional education: Effects on professional practice and health care outcomes (update). Cochrane Database of Systemic Reviews, Issue 3, Art. No.: CD00213. DOI: 10.2002/14651858.CD002213

Ruiz, M. G., Ezer, H. \& Purden, M. (2013). Exploring the nature of facilitating interprofessional learning: Findings from an exploratory study. Journal of Interprofessional Care 27(6):489-495. Doi: 10.3109/13561820.2013.811640

Sanyal, R. (2012). Dean’s forum. American Journal of Business, 27(2). doi: 10.1108/ajb.2012.54027baa.002 
Sargeant, J. (2009). Theories to aid understanding and implementation of interprofessional education. The Journal of Continuing Education in the Health Professions, 29(3), 178184. doi: $\underline{10.1002 / \text { chp. } 20033}$

Sargeant, J., Hill, T., \& Breau, L. (2010). Development and testing of a scale to assess interprofessional (IPE) facilitation skills. Journal of Continuing Education in the Health Professions, 30(2), 126-131. http://dx.doi.org/10.1002/chp.20069

Shrader, S., Mauldin, M., Hammad, S., Mitcham, M., \& Blue, A. (2015). Developing a comprehensive faculty development program to promote interprofessional education, practice and research at a free-standing academic health science center. Journal of Interprofessional Care, 1-3. doi: 10.3109/13561820.2014.940417

Silver, I. L., \& Leslie, K. (2009). Faculty development for continuing interprofessional education and collaborative practice. The Journal of Continuing Education in the Health Professions, 29(3), 172-177. doi: 10.1002/chp.20032

Steinert, Y. (2005). Learning together to teach together: interprofessional education and faculty development. Journal of Interprofessional Care, 19(Suppl 1), 60-75. doi: $\underline{10.1080 / 13561820500081778}$

Steinert, Y., Mann, K., Centeno, A., Dolmans, D., Spencer, J., Gelula, M., \& Prideaux, D. (2006). A systematic review of faculty development initiatives designed to improve teaching effectiveness in medical education: BEME Guide No. 8. Medical Teacher, 28(6), 497-526. doi: 10.1080/01421590600902976

Steinert, Y., Boudreau, J.D., Boillat, M., Slapcoff, B., Dawson, D., Briggs, A., \& Macdonald, M.E. (2010). The Osler Fellowship: An apprenticeship for medical educators. Academic Medicine, 85(7), 1242-9. doi: 10.1097/ACM.0b013e3181da760a. 
Steinert, Y., Naismith, L., \& Mann, K. (2012). Faculty development initiatives designed to promote leadership in medical education: BEME Guide No. 19. Medical Teacher, 34(6), 483-503. doi: 10.3109/0142159X.2012.680937

Thiedke, C., Blue, A.V., Chessman, A.W., Keller, A.H. \& Mallin, R. (2004). Student observations and ratings of preceptor's interactions with patients: The hidden curriculum. Teaching and Learning in Medicine: An International Journal, 16:4, 312-316, doi: 10.1207/s15328015tlm1604_2

Wagner, E.H. (2000). The role of patient care teams in chronic disease management. BMJ. 320(7234), 569-572. http://dx.doi.org/10.1136/bmj.320.7234.569

Zorek, J. \& Raehl, C. (2013). Interprofessional education accreditation standards in the USA: A comparative analysis. Journal of Interprofessional Care, 27(2), 123-130. doi: 10.3109/13561820.2012.718295. 